\title{
CHAPTER 109
}

\section{SEDIMENT POLLUTION IN COASTAL WATERS}

\author{
J van de Kreeke*
}

ABSTRACT

Sediment pollution can be defined as the increase in sediment concentration, due to artificial infusion of sediment, to a level harmful to fish and plant $11 \mathrm{fe}$

The coastal engineer may be called upon to evaluate the result of an artificial sediment influx in terms of characteristic parameters 11ke concentration and turbidity and to determine eventual deposition areas of the sediment

This paper describes the field investigations carried out to evaluate a case of sediment infusion in one of the estuaries on the US east coast The sediment was discharged via a pipeline at a rate of approximately $10 \mathrm{lbs} / \mathrm{sec}$ Nearly all the released sediment was in the silt range In addition to the results of the field measurements a simple mathematical mode 1 is presented, describing the temporal and spatial distribution of the sediment in the resulting sediment plume

\section{DESCRIPTION OF THE STUDY AREA}

The study area is located in a bend of the estuary, see Figure 1 The depth contours in this figure show a deep channel at the west side and a relative shallow plateau at the east side of the estuary The hydraulic environment in the study area is governed by the tide and the freshwater inflow The tide has a semidiurnal character $w 1$ th a mean tidal range of $21 \mathrm{ft}$ and a mean spring tidal range of $24 \mathrm{ft}$ Maximum currents are on the order of $1 \mathrm{ft} / \mathrm{sec}$, both for ebb and flood, but the ebb currents can be considerably higher during periods of high freshwater inflow An order of magnitude of the freshwater discharge might be obtained from the following figures During $50 \%$ of the time the average daily freshwater discharge is higher than $6,500 \mathrm{cfs}$ and during $1 \%$ of the time exceeds $70,000 \mathrm{cfs}$ For comparison, the maximum tidal discharge in the study area is on the order of 100,000 cfs Salinities in the shallow part, the area where the sediment is released, can be as high as $2 \%$ o after long periods of low freshwater inflow and as low as $01 \%$ o after periods of high freshwater inflow The water 15 well mixed, at least for the shallow depths

In order to gather additional information on the hydraulic environment in the study area, current measurements were carried out with a stationary and a movable current meter Both instruments were equipped with a Savonius rotor In addition, the stationary meter had a direction device The readout of the movable current meter provided a record of instantaneous velocities

*Research Associate, Dept of Coastal and 0ceanographic Engineering, University of Florida 


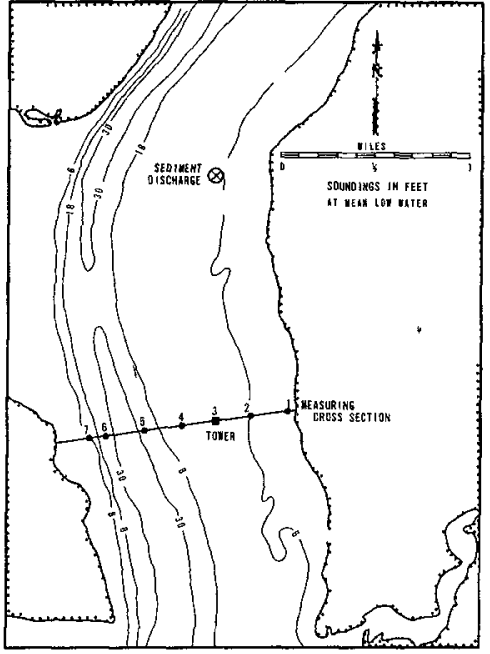

FIGURE 1 - STUOY AREA AND MEASURING STATIONS

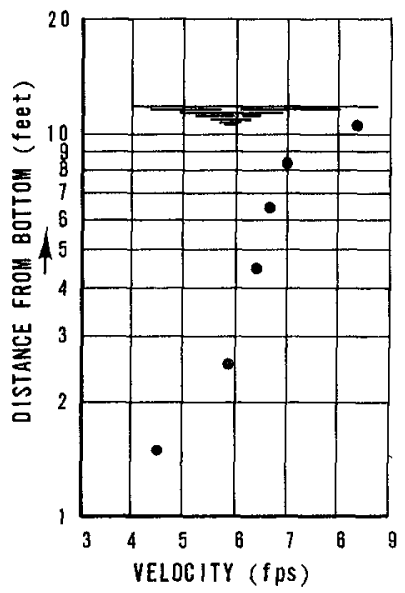

FIGURE 2 - MEASUREO VELOCITY PROFILE IN STATION 3
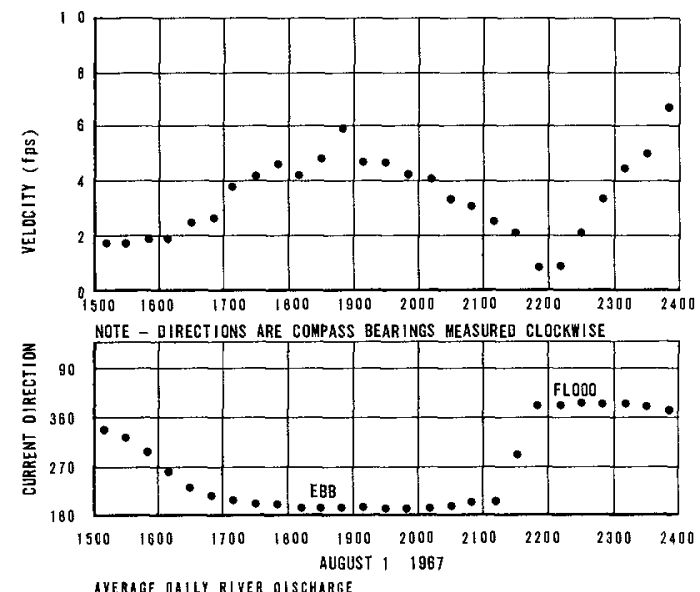

AUGUST $1-5240 \mathrm{cfs}$

FiguRE 3 - CURRENT VeldCITY aNd OIRECTION MEASUREd IN STATION 3 
The output of the stationary current meter consisted of velocities and directions averaged over time periods of 19 minutes Calibration threshold for the rotor and direction device was approximately $01 \mathrm{ft} / \mathrm{sec}$ The stationary meter was placed in a tower, for location see Figure 1, with the center of the rotor $15 \mathrm{ft}$ and the center of the vane $3 \mathrm{ft}$ above the bottom The movable meter was used to determine the velocities at the stations 1-7, indicated in Figure 1 The measurements with the movable current meter were carried out during periods of definite ebb currents It was hoped that by comparing measured and theoretical velocity profiles, an estimate could be made of the eddy diffusivity coefficient This idea had to be abandoned, however, since the measured profiles did not comply with the theoretical logarithmic velocity distribution as may be seen from Figure 2

Typical curves showing the variation in current velocity and direction during a tidal cycle are presented in Figure 3 Attention is drawn to the magnitudes and direction of the currents during slack tide The transverse currents during these periods are one of the reasons why the sediment plume seems to disappear during periods of slack tide, as will be described later

\section{NATURAL SEDIMENT CONTENT IN THE ESTUARY}

To determine the background sediment load in the study area, suspended load samples were taken when no sediment infusion took place The samples were taken with a device consisting of two bottles connected by a short piece of pipe, see Figure 4 The lower bottle contains the sample while the displaced air is contained in the upper bottle The whole system is buoyant even when the lower bottle is filled A weight connected with the sampler by an anchor line is used to lower the sampler When the weight reaches the bottom, the tension in the retrieval inne is released, which automatically opens the intake The positioning of the sampler above the bottom 15 controlled by the length of the anchor line

The sedtment samples were analyzed using the following procedure The suspension was we $11 \mathrm{~m} 7 x e d$ and $500 \mathrm{~m} 7$ was poured into a cylinder The suspended solids were then collected on filter paper The filter paper was dried in an oven When dry, the paper was burned and the ashes weighed

The sediment samples were taken at three different depths at the stations used for the current measurements The various sampling series were carried out for different freshwater discharges in order to study the influence of the freshwater inflow on the sediment content All samples were taken during periods of definite ebb current As an example, the results of one of the sampling series is plotted in Figure 5 It is noted that the data for the bottom samples are probably not very reliable, chances are that the sampler was in the mud layer covering the bottom instead of just above this layer

In Figure 6 , the average sediment concentration for each sampling series, that 15 the average of all 7 sampling stations, 15 plotted versus the average dally freshwater inflow In the averaging procedure, bottom samples were neglected for the reason mentioned in the previous paragraph Although only five data points are avallable, it may be safely concluded that a definite relation exists between sediment content and freshwater inflow Because of the 


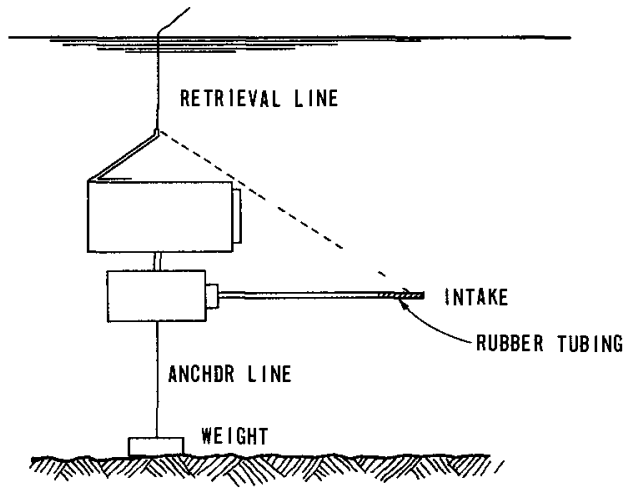

FIGURE 4 - SUSPENDED LDAD SAMPLER

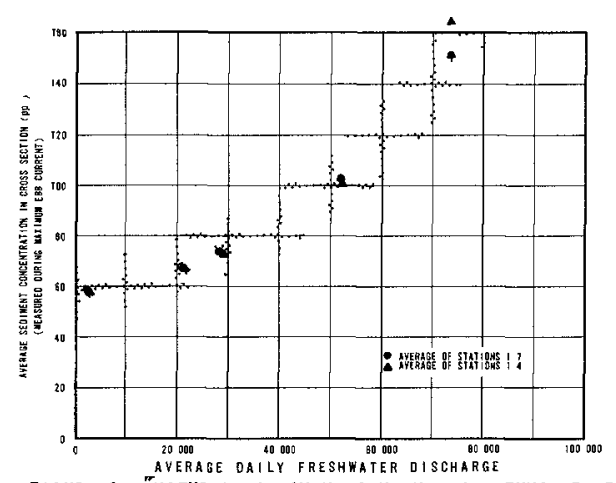

FIGURE 6 -"NATURAL SEDIMENT CDNTENT AS A FUNCTIDN DF FRESHWATER INFLDW

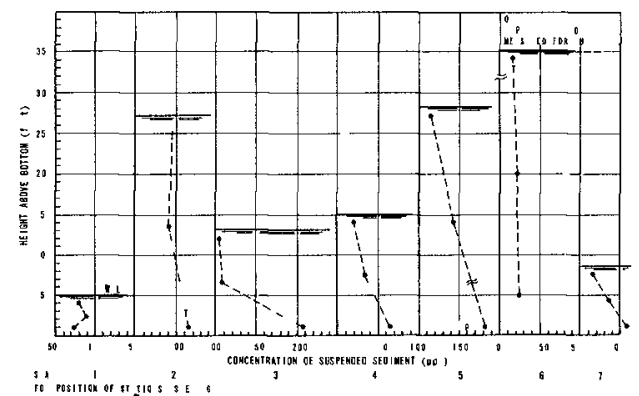

FIGURE 5 - NATURAL SUSPENDED SEDIMENT CDNCENTRATIDN IN DIFFERENT MEASURING STATIDNS

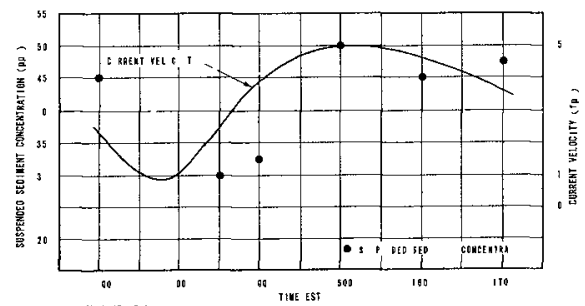

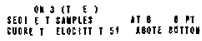

FIGURE 7 - VARIATIDN IN SUSPENDED SEDIMENT CONCENTRATIDN DURING A TIDAL CYCLE 
special importance of the natural sediment in the area of sediment infusion, the average sediment concentration for stations 1 through 4 on ly, neglecting again the bottom samples, were also plotted versus the freshwater inflow in the same figure No significant differences exist between the average sediment concentration in the shallow area (stations 1-4) and the average sediment concentration when regarding the total estuary cross-section (stations 1-7)

To study the variation in sediment concentration during a tidal cycle, a series of samples was taken at station No 3 (tower) at a depth of $6 \mathrm{ft}$ each hour for a period of six hours The results are shown in Figure $7 \mathrm{~A}$ definite variation in suspended sediment content with the tidal currents seems to exist. This agrees with observations by other investigators, see Nichols and Poor [3] At the time of the measurements, $1 t$ was observed that during periods of high velocity the water looked cloudy while during slack tide the water had a less turbid appearance

\section{CHANGES IN THE \\ SEDIMENT FIELD DUE TO THE SEDIMENT INFLUX}

The sediment was discharged via a pipeline on the shallow plateau, see Figure 1 The discharge point was approximately $10 \mathrm{ft}$ below the water surface The total discharge was on the order of $107 \mathrm{bs}$ of solids/sec Most of the discharged material appeared to be $1 n$ the silt range, $90 \%$ of the particles are smaller than $85 \mu$, the median particle diameter $1545 \mu$ and $10 \%$ of the particles are smaller than $10 \mu$ The sediment influx resulted in a plume visible during periods of relative low turbidity of the receiving waters $V_{1}$ sual observations, which are of course restricted to what happens at the surface, indicated that the end of the plume moved approximately with the speed of the current The maximum length of the plume, just before slack tide, was approximately 3 miles The width of the plume remained practically constant At slack tide, the discoloring disappeared indicating that the sediment had settled or was dispersed by the reversing tide

Sediment samples were taken to determine more accurately the effect of the sediment influx The samples were taken in the measuring stations 1-7 and along the center line of the sediment plume As an example, the distribution of suspended sediment across the estuary 15 presented in Figure 8 This figure clearly shows an increase in suspended load at the stations $2 A$ and 3 The influence of the sediment infusion still is restricted to a narrow band at this distance

Sediment concentrations in the axis of the plume are indicated in Figure 9 , the concentrations decrease rapidly with downstream distance The concentration near the discharge point varied between $1000 \mathrm{ppm}$ and $1500 \mathrm{ppm}$ and is already decreased to 200-500 ppm at a distance of $400 \mathrm{ft}$ downstream of the discharge point

It $1 \mathrm{~s}$ clear from Figure $g$ that large amounts of sediment settle close to the point of release Fluorescent tracer was used to gain insight into the deposition areas of the remainder of the sediment The range of particle sizes of the tracer material covered approximately that of the released sediment 


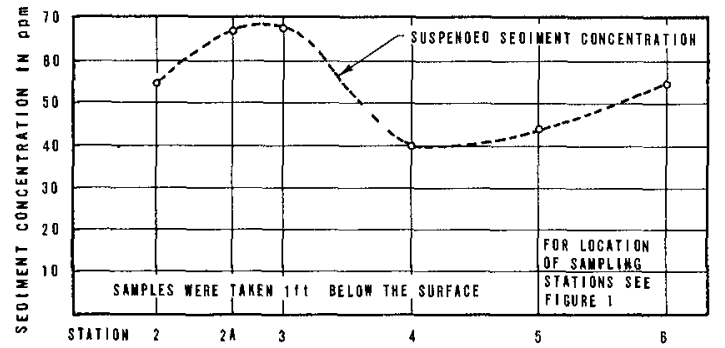

FIGURE 8 - HORIZONTAL DISTRIBUTIDN DF SUSPENDEO SEDIMENT

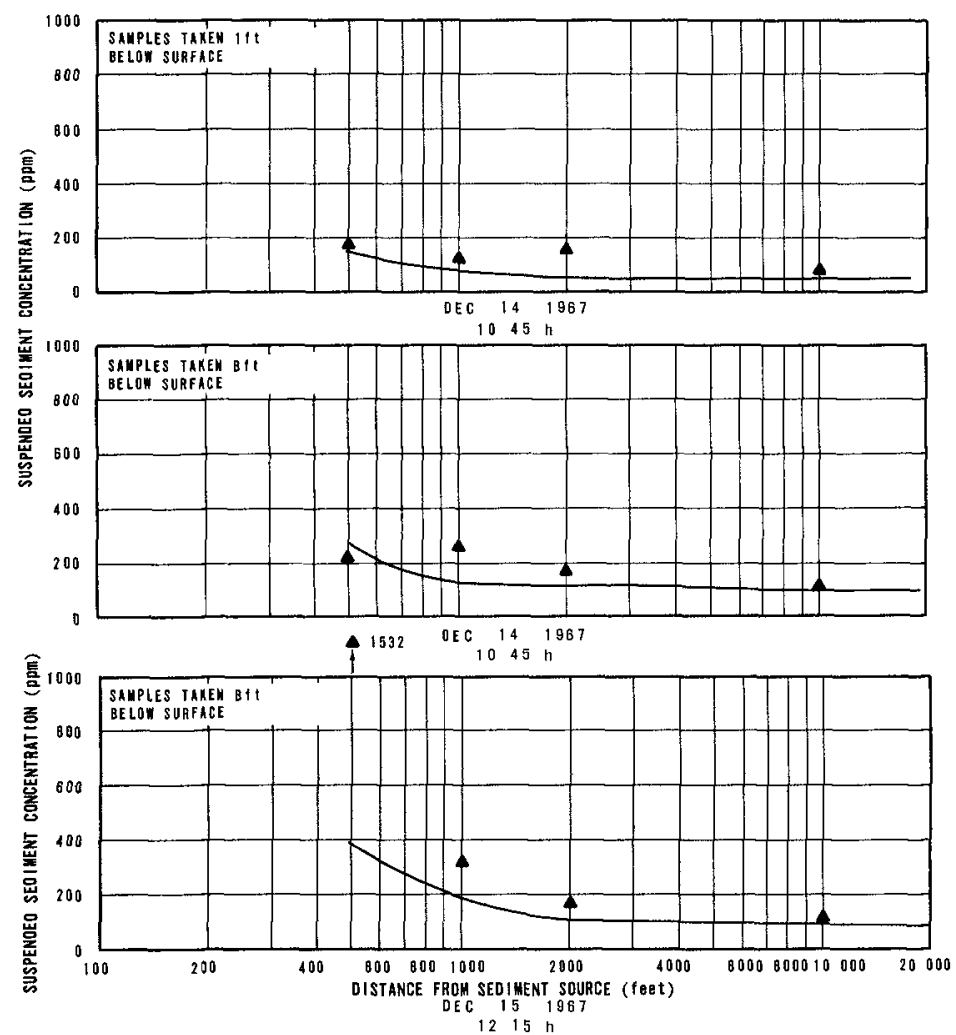

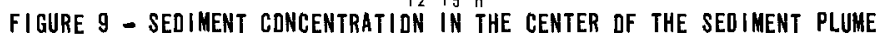


The tracer was released at the location of the sediment discharge point, at a rate of approximately $081 \mathrm{bs} / \mathrm{min}$ for a period of two hours, leading to a total amount of released tracer of $100 \mathrm{lbs}$ The same day and the next day, suspended load samples were taken at different depths in the study area The results were somewhat meager, probably because of the relative small quantity of tracer material, but some tracer grains were found as far away as stations 1 and 5 of the measuring cross-section

\section{MATHEMATICAL DESCRIPTION}

Assuming that lateral and longitudinal diffusion are negligible (as suggested by the results of the measurements), and furthermore assuming a gradient type diffusion, the conservation of matter equation may be written as

$$
\frac{\partial \phi}{\partial t}=\frac{\partial\left(\varepsilon \frac{\partial \phi}{\partial y}\right)}{\partial y}-u \frac{\partial \phi}{\partial x}+w \frac{\partial \phi}{\partial y}
$$

in which $\phi=$ sediment concentration

$$
\begin{aligned}
\varepsilon & =\text { diffusion coefficient } \\
u & =\text { current velocity } \\
W & =\text { fall velocity of a sediment particle }
\end{aligned}
$$

The coordinate system has its origin at the bottom, the horizontal $x$-axis is positive in the current direction, the vertical $y$-axis is positive upward Attempts to arrive at a computer solution for Equation (1) indicated that, with conventional numerical methods and for the dimensions of the computational field encountered in this study (water depth $10 \mathrm{ft}$, length of the sediment plume 20,000 ft), it is questionable whether even the larger computers can handle this problem Therefore, a simplified and admittedly more crude model is presented here to describe the sediment concentration in the plume

It is assumed that a block of polluted water travels at the average current velocity $u(t)$, and thus the position $x$, of the block at time $t$ is $x=u t$ Only vertical diffusion is considered It is also assumed that all particles reaching the bottom stick to $1 t$, while a steady sediment source at the bottom of the moving block of polluted water simulates the stir-up capacity of the flow Only periods of definite ebb and flood current are considered It is assumed that during periods of slack tide, the sediment particles in the plume settle and/or are distributed over the width of the estuary

In deriving the equations, it is assumed that

- The convective velocity $u(t)$ is constant over the depth

- The eddy diffusivity coefficient $\varepsilon$ is constant 
- The fluid properties are not altered by the suspended sediment

- The diffusion is proporicional to the gradient of the concentration

- The sediment concentration in the vertical at the dredging site is constant

- No flocculation occurs

The coordinate system is the same as the one described in the previous paragraph Time $(t)$ is zero at the moment the block of polluted water leaves the dredge For the above assumptions the equations relating the sediment concentration $\phi(y, t)$ and the independent variables $y$ and $t$ are

Field equation

$$
\frac{\delta \phi}{\delta t}=\varepsilon \frac{\delta^{2} \phi}{\delta y^{2}}+W \frac{\delta \phi}{\delta y}
$$

Boundary conditions

$$
y=0 \quad \varepsilon \frac{\delta \phi}{\delta y}=-\lambda
$$

in which $\lambda=$ rate of erosion

$$
y=h \quad \varepsilon \frac{\delta \phi}{\delta y}=-W \phi
$$

in which $h=$ average depth

For a more detailed discussion of the boundary condition, see Partheniades [2]

Initial condition

$$
\mathrm{t}=0 \quad \phi=\phi_{0}
$$

The solution of the above system of equations is

$$
\phi=\frac{\lambda}{W} e^{-2 a y}+\sum_{n=1}^{\infty} B(n) e^{-a y}\left[\cos \alpha_{n} y+\frac{a}{\alpha_{n}} \sin \alpha_{n} y\right] e^{-\left(\alpha_{n}{ }^{2}+a^{2}\right) \varepsilon t}
$$

in which

$$
\alpha_{n}{ }^{\prime} s \text { are the solution of } \operatorname{tg} \alpha_{n} h=\frac{2 \alpha_{n}{ }^{a}}{\alpha_{n}^{2}-a^{2}} \quad \alpha_{n}>0
$$

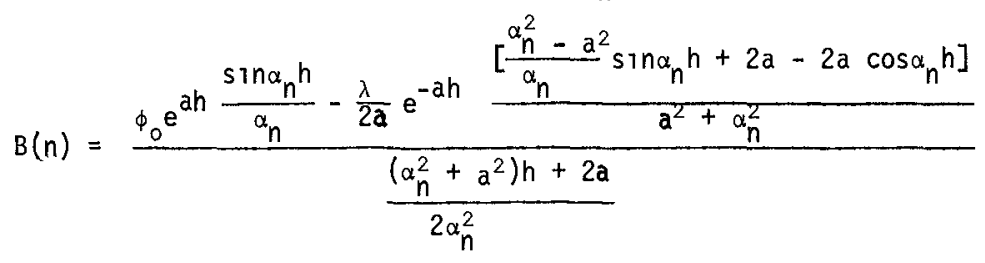

$a=\frac{W}{2 \varepsilon}$ 
Note that the second term in the solution goes to zero for large values of $t$, the first term represents the natural sediment concentration

To check the validity of the model a comparison is made between measured and computed concentrations In the computations, $\phi=1250 \mathrm{ppm}$ The value of $\lambda$ was obtained by assuming a natural sediment concentration $\phi=100 \mathrm{ppm}$ at $y=4 \mathrm{ft}$ The average depth $h=10 \mathrm{ft}$ An estimate of the diffusion coefficient was made by using Elders [1] expression

$$
\varepsilon=0068 \mathrm{hu}_{*}
$$

in which $u_{*}=$ shear velocity

In the computations, $\varepsilon=005 \mathrm{ft}{ }^{2} / \mathrm{sec}$ is used The value $W=0008 \mathrm{ft} / \mathrm{sec}$ was taken as a representative value of the fall velocity of the particle distribution Computed and measured concentrations are plotted in Figure 9 The results agree reasonably well in spite of the many assumptions made in deriving the mathematical description and the $11 \mathrm{~m}$ ted accuracy of the measurements

\section{CONCLUSIONS}

The artificial sediment infusion results in a sediment plume visible during periods of low turbidity of the recelving waters The end of the plume moves approximately with the speed of the current The width of the plume remains practically constant The sediment concentration in the plume decreases rapidiy with increasing distance from the point of sediment influx During periods of slack tide, the plume disappears, the sediment settles and at the same time is dispersed by secondary currents

A crude mathematical model is presented describing the sediment concentration in the plume In 7 ts present form, it should be mainly regarded as a first step to a rational and universal solution

Finally, it is noted that the title of the paper is somewhat of a misnomer as the case of sediment infusion discussed here has never been proven to be harmful

\section{ACKNOWLEDGEMENT}

The study described here was carried out by the author while employed with Sclence Engineering Associates, San Marino, California The guidance of $\mathrm{Dr}$ Per Bruun during the initial stages of the project is gratefully acknowledged

\section{REFERENCES}

1 Elder, J, "The Dispersion of Marked Fluid in Turbulent Shear Flow", J Fluid Mech, Vol 5, Part 5, 1959 
2 Partheniades, E, "A Summary of the Present Knowledge of the Behavior of Fine Sediments in Estuaries", Technical Note No 8, M I T , Hydrodynamics Laboratory, June, 1964

3 Nichols, M $M$ and Poor, $G$, "Sediment Transport in a Coastal Plain Estuary," Journal of the Waterways and Harbors Division, ASCE, Vol 93, No WW4, November, 1967 